\title{
Transcarotid access route: a first-choice option for nontransfemoral transcatheter aortic valve implantation
}

\author{
Federico Conrotto, Francesco Bruno, Fabrizio D'Ascenzo \\ Cardiovascular and Thoracic Department, Division of Cardiology, Città della Salute e della Scienza, Turin, Italy
}

RELATED ARTICLE

by Hudziak et al, see p. 31

Correspondence to: Federico Conrotto, MD, Cardiovascular and Thoracic Department, Division of Cardiology, Città della Salute e della Scienza, Corso Bramante 88/90, 10126, Torino, Italy, phone: +390116336023, email: federico.conrotto@gmail.com Received: January 6, 2021. Accepted: January 7, 2021. Published online: January 25, 2021. Kardiol Pol. 2021; 79 (1): 3-4 doi:10.33963/KP.15765 Copyright by the Author(s), 2021
We read with interest the study by Hudziak et $\mathrm{al}^{1}$ that appeared in the current issue of Kardiologia Polska (Kardiol Pol, Polish Heart Journal).

Transcatheter aortic valve implantation (TAVI) has been increasingly used for the treatment of severe aortic stenosis. It surpasses isolated surgical valve replacement in high- and medium-risk patients and has been recently introduced also in low-risk patients with excellent outcomes in terms of long-term valve durability. ${ }^{2-4}$ Over time, several factors have been related to prognosis in patients undergoing TAVI, 5,6 but the choice of the best access route remains one of the key points for procedural success. ${ }^{7}$

Transfemoral access is the safest and widely used approach for TAVI procedures and its feasibility should be assessed before choosing between TAVI and surgical valve replacement. ${ }^{8}$ However, despite improvement in procedural techniques and device profiles, transfemoral access cannot be performed in approximately $10 \%$ to $15 \%$ of patients because of arterial tortuosity, severe calcifications, iliofemoral arteriopathy, aortic aneurysm, or previous vascular surgery.

Alternative nonfemoral approaches have been developed, with transcarotid access representing a new and attractive one. ${ }^{9}$ It provides a relatively straightforward path from the common carotid artery to the aortic annulus and helps to avoid difficulties associated with the long, tortuous access of peripheral sites.

In their study, Hudziak et $\mathrm{al}^{1}$ reported the results of a short-term comparison of 265 consecutive high-risk patients undergoing TAVI (transcarotid in 33 patients and transfemoral in 232) in their institution between 2017 and 2019. The baseline characteristics of the 2 study groups were similar except a higher New York Heart Association functional class, more frequent peripheral artery disease, and a higher EuroSCORE II in the transcarotid TAVI group.

Periprocedural and short-term outcomes were similar in both groups, and transcarotid TAVI was associated with shorter procedural time (65 vs 90 minutes) and a more frequent use of general anesthesia (100\% vs $47 \%)$. The short-term outcomes reported by Hudziak et $\mathrm{al}^{1}$ are excellent and consistent with the results of the most recent meta-analysis of transcarotid TAVI, ${ }^{10}$ which reported a pooled 30 -day mortality of $6.7 \%$ (6\% in the present study), a transient ischemic attack/ stroke rate of $3.1 \%$ (3\% in the present study, only a single case of TIA), a permanent pacemaker implantation rate of $16.7 \%$ ( $15.1 \%$ in the present study); the latter still represents a significant pitfall of the TAVI procedure. ${ }^{11}$ No major vascular complications or major bleedings were noted in the transcarotid TAVI group in the study by Hudziak et al, ${ }^{1}$ while the meta-analysis showed the rates of $2.5 \%$ and $7 \%$, respectively. ${ }^{10}$ These results confirm the safety and efficacy of transcarotid access as an alternative for patients who cannot undergo transfemoral TAVI.

Compared with other nonfemoral routes, carotid access holds its distinct benefits in selected patients: 1 ) it permits a direct route to the aortic valve with a shorter distance between the access point and the aortic annulus; 2) it enhances sheath delivery and catheter stability; and 3) it enables a more accurate prosthesis positioning compared with femoral access. On the other hand, the transapical approach requires thoracotomy and left ventricular puncture, it is unsuitable for patients with severe respiratory or 
left ventricular dysfunction, and it has been associated with worse outcomes. ${ }^{5}$ The transaortic route requires ministernotomy and it is unsuitable in patients with severe respiratory problems or those with the heavily calcified ascending aorta. The transaxillary approach represents a valid peripheral alternative to the transcarotid approach, but it remains inappropriate for patients with severe subclavian or axillary artery disease. ${ }^{12}$ Moreover, in a recent propensity-matched study, transcarotid TAVI was associated with similar mortality and a significant reduction in stroke rates compared with the transaxillary approach. ${ }^{13}$

Considering the manipulation of the carotid artery, periprocedural stroke is one of the feared complications of the procedure. In addition to the well-known stroke causes in transfemoral TAVI, such as dislodgement of calcified debris or the aortic valve tissue and manipulation of catheters, transcarotid TAVI carries an additional factor contributing to stroke risk related to transient cerebral blood flow reduction and local complications involving the carotid artery. However, in their analysis, Hudziak et al ${ }^{1}$ reported excellent results, similar to those presented in the literature and to the rate of stroke in transfemoral TAVI. ${ }^{10,12}$ As already underlined by the authors, a careful preoperatory procedure planning with the use of computed tomography and a meticulous intraoperative cerebral blood flow monitoring with cerebral oximetry and backflow pressure measurement are mandatory to reduce the incidence of stroke, especially when general anesthesia is used. ${ }^{14}$ In fact, transcarotid access, unlike the transfemoral approach, is achieved under general anesthesia in most of the cases. Although a previous large, randomized trial showed no significant differences in stroke rates between local and general anesthesia in patients undergoing carotid endarterectomy ${ }^{15}$, local anesthesia should be encouraged also for transcarotid TAVI in order to enable the real-time assessment of neurologic status and potentially minimize cerebral hypoperfusion in high-risk patients.

Finally, vascular complications seem to be very rare after transcarotid TAVI and apparently lower compared with transfemoral TAVI. ${ }^{12}$ These findings together with the possibility of early patient mobilization are crucial to reduce hospitalization time and achieve good outcomes using transcarotid access.

In conclusion, transcarotid access is safe and provides short-term outcomes superimposable on those of transfemoral TAVI. It may be considered a first-choice alternative approach for TAVI when transfemoral access is unsuitable. Operator expertise, periprocedural planning, and procedural monitoring are necessary to achieve good clinical outcomes. With the increasing use of transcarotid TAVI in patients with unfavorable anatomy, there is hope that dedicated devices for transcarotid access will be designed to optimize vascular access and valve deployment. This will be of particular importance considering the expansion of TAVI to patients at lower surgical risk.

\section{ARTICLE INFORMATION}

DISCLAIMER The opinions expressed by the author(s) are not necessarily those of the journal editors, Polish Cardiac Society, or publisher.

CONFLICT OF INTEREST None declared.

OPEN ACCESS This is an Open Access article distributed under the terms of the Creative Commons Attribution-NonCommercial-NoDerivatives $4.0 \mathrm{In}$ ternational License (CC BY-NC-ND 4.0), allowing third parties to download articles and share them with others, provided the original work is properly cited, not changed in any way, distributed under the same license, and used for noncommercial purposes only. For commercial use, please contact the journal office at kardiologiapolska@ptkardio.pl.

HOW TO CITE Conrotto F, Bruno F, D'Ascenzo F. Transcarotid access route: a first-choice option for nontransfemoral transcatheter aortic valve implantation. Kardiol Pol. 2021; 79: 3-4. doi:10.33963/KP.15765

\section{REFERENCES}

1 Hudziak D, Wojakowski W, Malinowski M, et al. Comparison of the short-term safety and efficacy of transcarotid and transfemoral access routes for transcatheter aortic valve implantation. Kardiol Pol. 2021; 79: 31-38.

2 Mack MJ, Leon MB, Thourani VH, et al. Transcatheter aortic-valve replacement with a balloon-expandable valve in low-risk patients. N Engl J Med. 2019; 380: 1695-1705.

3 Popma JJ, Deeb GM, Yakubov SJ, et al. Transcatheter aortic-valve replacement with a self-expanding valve in low-risk patients. N Engl J Med. 2019; 380: 1706-1715.

4 Piroli F, Franchin L, Bruno F, et al. New advances in the prevention of transcatheter aortic valve implantation failure: current and future perspectives. Kardiol Pol. 2020; 78: 842-849.

5 D'Ascenzo F, Conrotto F, Salizzoni S, et al. Incidence, predictors, and impact on prognosis of systolic pulmonary artery pressure and its improvement after transcatheter aortic valve implantation: a multicenter registry. I Invasive Cardiol. 2015; 27: 114-119.

6 Conrotto F, Salizzoni S, Andreis A, et al. Transcatheter aortic valve implantation in patients with advanced chronic kidney disease. Am J Cardiol. 2017; 119: 1438-1442.

7 Conrotto F, D'Ascenzo F, Giordana F, et al. Impact of access on TAVI procedural and midterm follow-up: a meta-analysis of 13 studies and 10,468 patients. J Interv Cardiol. 2014; 27: 500-508.

8 Baumgartner H, Falk V, Bax JJ, et al. 2017 ESC/EACTS guidelines for the management of valvular heart disease. Eur Heart J. 2017; 38: 2739-2791.

9 Mylotte D, Sudre A, Teiger E, et al. Transcarotid transcatheter aortic valve replacement: Feasibility and safety. JACC Cardiovasc Interv. 2016; 9: 472-480.

10 Sharma SP, Chaudhary R, Ghuneim A, et al. Carotid access for transcatheter aortic valve replacement: a meta-analysis. Catheter Cardiovasc Interv. 2020 Sep 5. [Epub ahead of print].

11 Bruno F, D'Ascenzo F, Pio Vaira M et al, Predictors of pacemaker implantation after TAVI according to kind of prosthesis and risk profile: a systematic review and contemporary meta-analysis. Eur Heart J Qual Care Clin Outcomes. 2020 Dec 8. [Epub ahead of print].

12 Beurtheret S, Karam N, Resseguier N, et al. Femoral versus nonfemoral peripheral access for transcatheter aortic valve replacement. J Am Coll Cardiol. 2019; 74: 2728-2739.

13 Kirker E, Korngold E, Hodson RW, et al. Transcarotid versus subclavian/axillary access for transcatheter aortic valve replacement with SAPIEN 3. Ann Thorac Surg. 2020; 110: 1892-1897.

14 Debry N, Delhaye C, Azmoun A, et al. Transcarotid transcatheter aortic valve replacement: general or local anesthesia. J Am Coll Cardiol Intv. 2016; 9: 2113-2120.

15 Lewis SC, Warlow CP, Bodenham AR, et al. General anaesthesia versus local anaesthesia for carotid surgery (GALA): a multicentre, randomised controlled trial. Lancet. 2008; 372: 2132-2142. 